\title{
Genetic Polymorphisms in the Locus Control Region and Promoter of GH1 Are Related to Serum IGF-I Levels and Height in Patients with Isolated Growth Hormone Deficiency and Healthy Controls
}

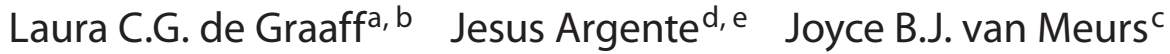 \\ André G. Uitterlinden ${ }^{c}$ Anita C.S. Hokken-Koelega ${ }^{a}$ b \\ ${ }^{a}$ Department of Pediatrics, Division of Endocrinology, Sophia Children's Hospital, ${ }^{\mathrm{b}}$ The Dutch Growth Foundation, \\ and ${ }^{\mathrm{C}}$ Department of Internal Medicine, Erasmus Medical Center, Rotterdam, The Netherlands; \\ ${ }^{\mathrm{d}}$ Department of Endocrinology, Hospital Infantil Universitario Niño Jesús (HNJ), Universidad Autónoma de Madrid,

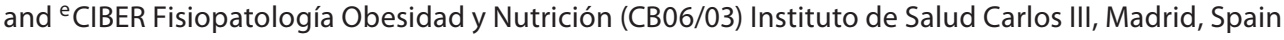

\section{Key Words \\ Growth hormone $\cdot$ Locus control region - Promoter $\cdot$ Single nucleotide polymorphism $\cdot$ Insulin-like growth factor 1}

\section{Abstract}

Background/Aims: Expression of the human growth hormone $(\mathrm{GH})$ gene $(G H 1)$ is regulated by a locus control region (LCR) and the highly polymorphic GH1 promoter. We analyzed $G H 1 \mathrm{LCR} /$ promoter single nucleotide polymorphisms (SNPs) in patients with isolated growth hormone deficiency (IGHD) in relation to clinical data. Methods: We directly sequenced the GH1 LCR/promoter of 62 Dutch IGHD patients without mutations or deletions in GH1 or GHRHR and of 72 controls with normal height. We related GH1 LCR/promoter SNPs to height, serum insulin-like growth factor 1 (IGF-I) levels and response to GH treatment. Results: In IGHD patients, promoter SNPs 6, 8 and 9 were associated with height and IGF-1 levels. In controls, SNPs 6 and 11 were associated with height. Homozygosity for the minor allele of SNP 9, associated with lower IGF-I levels in patients, was significantly more frequent among patients than among controls. Genotypes based on SNPs 6, 8, 9 and 11 explained $10.8 \%$ of IGF-I
SDS variation in IGHD patients and $15.9 \%$ of height SDS variation in controls. Conclusion: GH1 Promoter SNPs 6, 8 and 9 were associated with height and IGF-1 levels among patients, and SNPs 6 and 11 with height in controls.

Copyright $\odot 2010$ S. Karger AG, Base

\section{Introduction}

Human postnatal growth is determined by the interaction of various genetic and environmental factors, and results from the lengthening of bones via cellular divisions, which is mainly regulated by human growth hormone (GH). GH, secreted by the somatotrophs of the anterior pituitary gland, is a protein of 191 amino-acids (22 $\mathrm{kDa}$ ) with 2 disulfide bridges, which are important for its structure and bioactivity. GH synthesis and secretion are regulated by several hormones, reviewed by Goldenberg and Barkan [1]. GH releasing hormone is produced in the hypothalamus and stimulates $\mathrm{GH}$ production via binding to the GHRH receptor (GHRHR), which is located in the anterior pituitary. $\mathrm{GH}$ production is negatively regulated by the somatotropin release inhibiting factor, or so-

\section{KARGER}

Fax +4161306 1234

E-Mail karger@karger.ch

www.karger.com (c) 2010 S. Karger AG, Basel

$1663-2818 / 10 / 0731-0025 \$ 26.00 / 0$

Accessible online at:

www.karger.com/hrp
Laura de Graaff, MD, PhD

Department of Pediatrics, Division of Pediatric Endocrinology

Sophia Children's Hospital, Erasmus University Rotterdam, PO Box 2060

NL-3000 CB Rotterdam (The Netherlands)

Tel. +31 15260 4875, Fax +31 10463 6811, E-Maill.degraaff@erasmusmc.nl 
matostatin, and by insulin-like growth factor 1 (IGF-I), the end product of GH's action.

Mutations in the genes encoding GH and GHRHR (GH1 and GHRHR, respectively) can cause isolated growth hormone deficiency (IGHD) types IA, IB (OMIM No. 262400) and II (OMIM No. 173100). The frequency of GH1 and GHRHR mutations in IGHD patients varies between 0 and $32 \%$ among different countries [2-7]. Thus, in the best of cases, mutations in the coding regions of GH1 and GHRHR are only detected in one third of the IGHD patients.

GH1 is located in the human GH cluster, in which 5 genes are situated on chromosome 17. Human GH (GH1) lies at the $5^{\prime}$ end of the cluster and is mainly expressed in pituitary somatotrophs. The remaining 4 genes, placental growth hormone (GH2) and 3 chorionic somatomammotropins (CS1, CS2, and the pseudogene CS5 or CSHP1), are only expressed in the placenta.

The expression of $G H 1$ is regulated by a locus control region (LCR), located 14.5-32 kb upstream of the gene [8] and by the GH1 promoter. To date, 3 single nucleotide polymorphisms (SNPs) have been reported in the LCR [9], while the GH1 promoter is highly polymorphic [914].

Although, in general, SNPs do not necessarily cause disease, they have been associated with susceptibility to diseases [15-17] and to environmental toxins [18] by affecting splicing [19], allelic expression [20], nonsense-mediated mRNA decay [21] or transcription factor binding [22]. GH1 promoter SNPs have been associated with height $[9,10,12]$, bone density, bone loss and fetal growth restriction [23, 24]. In addition, some GH1 promoter SNPs have been associated with breast and colorectal cancer [13, 25-28]. Two promoter SNPs have been studied in relation to GH and/or IGF-I levels in patients with varying degrees of GH deficiency $[11,12]$.

The Dutch Hypothalamic and Pituitary Gene Study is a nation-wide multicenter study investigating genetic and other causes of 'idiopathic' growth hormone deficiency in the Dutch GH deficiency population. In order to explain the variability in our IGHD patients' phenotypes and their variable response to GH treatment, we analyzed GH1 LCR/promoter sequence variations in IGHD patients and looked for associations of these variations with height, serum IGF-I levels and height increases during the 1st year of GH treatment. We compared the data with those of a healthy Dutch control group. Since Hasegawa et al. [12] related the SNP 'P1' in GH1 intron 4 (dbSNP 2665802) with height, GH and IGF-I levels, we also included this polymorphism in our analysis.

\section{Patients and Methods}

We included 62 Dutch Caucasian patients diagnosed with IGHD based on a scoring system including height SDS (HSDS), maximum GH levels, IGF-I and IGFBP-3 SDS without mutations or deletions in GH1 or GHRHR [29]. Patients' clinical data were available from the Dutch National Registry of Growth Hormone Treatment, where auxologic and laboratory parameters have been documented.

GH and IGF-I measurements were centrally performed in 1 laboratory with published reference values [30] for $80 \%$ of the patients. For the remaining 20\%, the laboratory-specific reference values for IGF-I were used to calculate the SDS. We obtained approval from the medical ethics committees of all participating hospitals. Informed consent was obtained from all participating patients or their parents, if the patients were aged less than 18 years. Seventy-two healthy Caucasian Dutch young adults with a height SDS between -2 and +2 agreed to participate in DNA analysis as control subjects.

Genomic DNA, extracted from peripheral blood according to standard procedures, was used for direct sequencing of the GH1 LCR/promoter using an ABI 3100 Sequencer. A 1,231-bp fragment including the promoter of $\mathrm{GH} 1$ was amplified using forward primer 5'-GGGAGCCCCAGCAATGC-3' and reverse primer 5'TCTGCCTGCATTTTCGCTTCG-3' by Touchdown PCR, including denaturation for $10 \mathrm{~min}$ at $95^{\circ} \mathrm{C}$, amplification at 68 $61^{\circ} \mathrm{C}$ decreasing the annealing temperature by $1^{\circ} \mathrm{C}$ every $2 \mathrm{nd} \mathrm{cy}-$ cle and 25 subsequent cycles at $61^{\circ} \mathrm{C}$, followed by a 7 -min extension at $72^{\circ} \mathrm{C}$. This fragment was sequenced by forward primers $5^{\prime}-$ GGGAGCCCCAGCAATGC-3' and 5'-CTGTCTGGTGGGTGGAGGTTAAA- $3^{\prime}$, and reverse primers $5^{\prime}$-CACATTCAGAAGCCCCAAAC-3' and 5'-ACCCAACTTGTCCTCTCTTTA-3'.

Since Hasegawa et al. [12] related the SNP 'P1' (IVS4 +90 T/A, dbSNP 2665802) in GH1 intron 4 with height, GH and IGF-I levels, we included this polymorphism in our analysis. P1 genotypes were available for patients who had participated in the genetic screening of the coding regions of GH1 and GHRHR as part of the Hypothalamic and Pituitary Gene Study [29]. In these patients, exon 4 and intron 4 had been PCR-amplified with forward primer $5^{\prime}$-CCGTGAGTGGATGCCTTCTC-3' and reverse primer $5^{\prime}$-GTGAGTTCTCTTGGGTCAGG-3' (annealing temperature $57.7^{\circ} \mathrm{C}$ ), and the fragment had been screened by WAVE dHPLC at 62.1 and $62.6^{\circ} \mathrm{C}$, which were shown to accurately detect the P1 variant [29].

We used the GH1 gene nucleotide sequence obtained from GenBank (Accession No. J03071) as a control and we numbered the SNPs according to Horan et al. [9]. We obtained the reference LCR sequence from GenBank (Accession No. AF010280) and used LCR numbering according to Jin et al. [31]. Of the LCR/promoter SNPs, linkage disequilibrium represented by $\mathrm{R}^{2}$ and D' was analyzed using Haploview [32].

The associations between genetic and clinical parameters were analyzed by means of ANOVA and $\chi^{2}$ tests using SPSS Version 11.0. Response to GH treatment was defined as the increase in HSDS during the 1st year of GH treatment. The normality of the distribution of all analyzed parameters was assessed with the KolmogorovSmirnov and Shapiro-Wilk tests. When expected cell counts for comparison of genotype frequencies between patients and controls were below 5, we used Fisher's exact test instead of the $\chi^{2}$ test. Parameters that were not normally distributed were analyzed using the nonparametric Kruskall-Wallis test instead of ANOVA. 


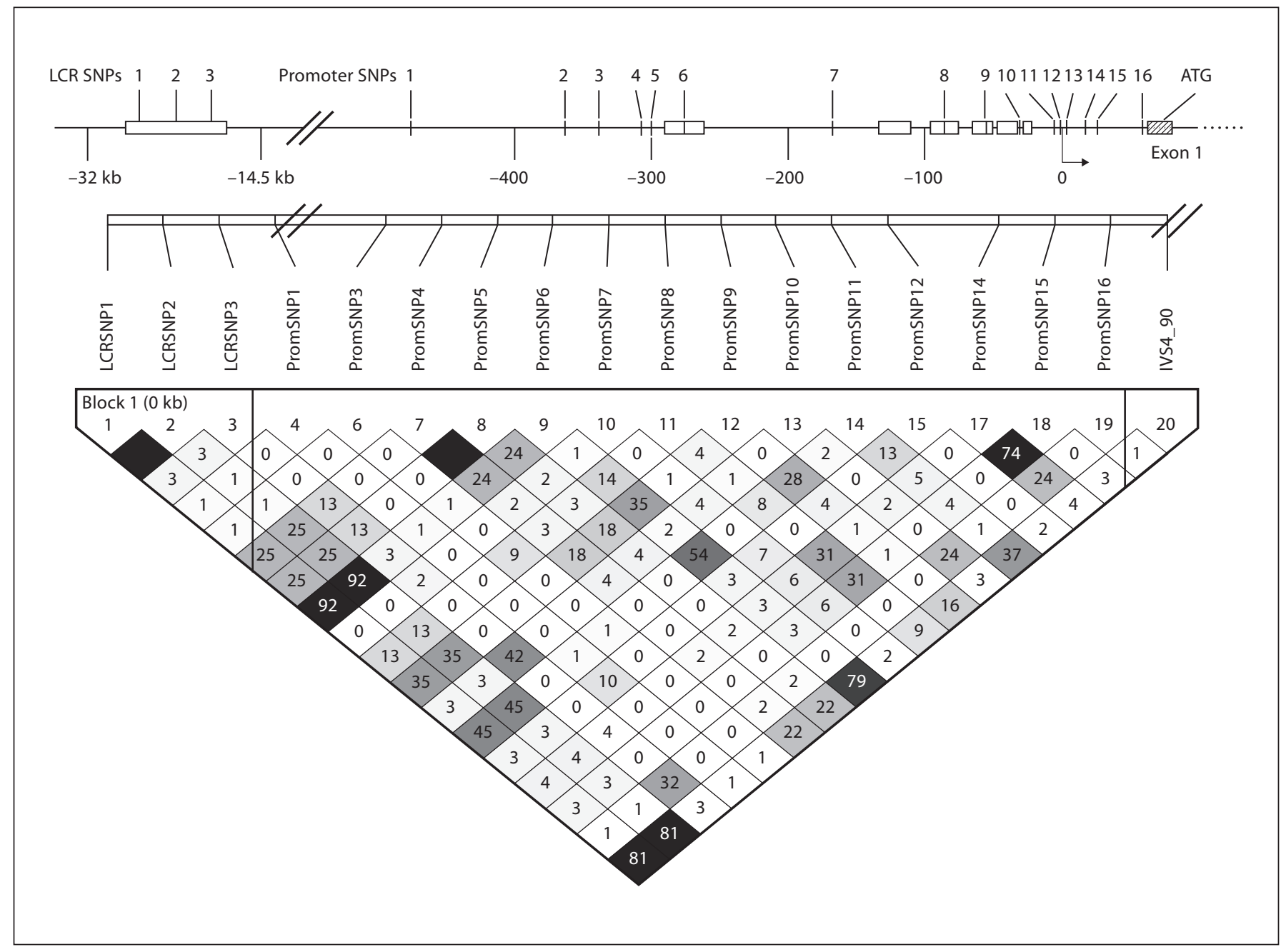

Fig. 1. LD plot showing linkage disequilibrium between $G H 1$ LCR, promoter and intronic SNPs. Black squares indicate SNPs that are in $100 \%$ LD ('highest possible correlation') with other SNPs. Dark and light gray squares represent lower levels of linkage disequilibrium, represented by $\mathrm{R}^{2}$ values in the squares. In the schematic representation of the GH1 LCR and promoter, open

\section{Results}

All LCR/promoter SNPs conformed with the HardyWeinberg equilibrium according to a $\chi^{2}$ test $(\mathrm{p}>0.05)$ except for promoter SNP $8(\mathrm{p}=0.01)$. In contrast to Horan et al. [9], we found that promoter SNP 2 was not polymorphic since all patients and controls carried the same allele. In patients and controls, there was a 100\% linkage disequilibrium between LCR SNP 1 and 2, and there was a 100\% linkage disequilibrium between promoter SNPs 4 and 5. Gene structure, sequence variation and linkage disequilibrium between LCR and promoter SNPs in our boxes represent binding sites (for PIT1, nuclear factor 1, vitamin $\mathrm{D}$ response element) and the TATA box, the hatched box with ATG represents the transcriptional initiation codon, and numbers represent SNP numbers. Prom = Promoter; IVS4_90 = intronic SNP 'P1' IVS4 +90 T/A; $0=1$ st base of GH1 cDNA sequence. patients is shown in figure 1. In patients and controls, promoter SNP 6 was strongly linked with LCR SNP1 (D' $0.96, \mathrm{R}^{2}$ 0.92; fig. 1). In patients, promoter SNP 6 was strongly linked with SNP 'P1' in intron 4 of GH1 (D' 0.95, $\mathrm{R}^{2}$ 0.72; $\mathrm{P} 1$ genotypes were not available for controls, see methods section).

Height in cases and controls, and serum IGF-I levels in patients were normally distributed. Four promoter SNPs were related with height and IGF-I levels. An overview of these SNPs, their rs numbers, alleles and their relations with clinical parameters are shown in tables 1 and 2 , as well as figure 2 . 


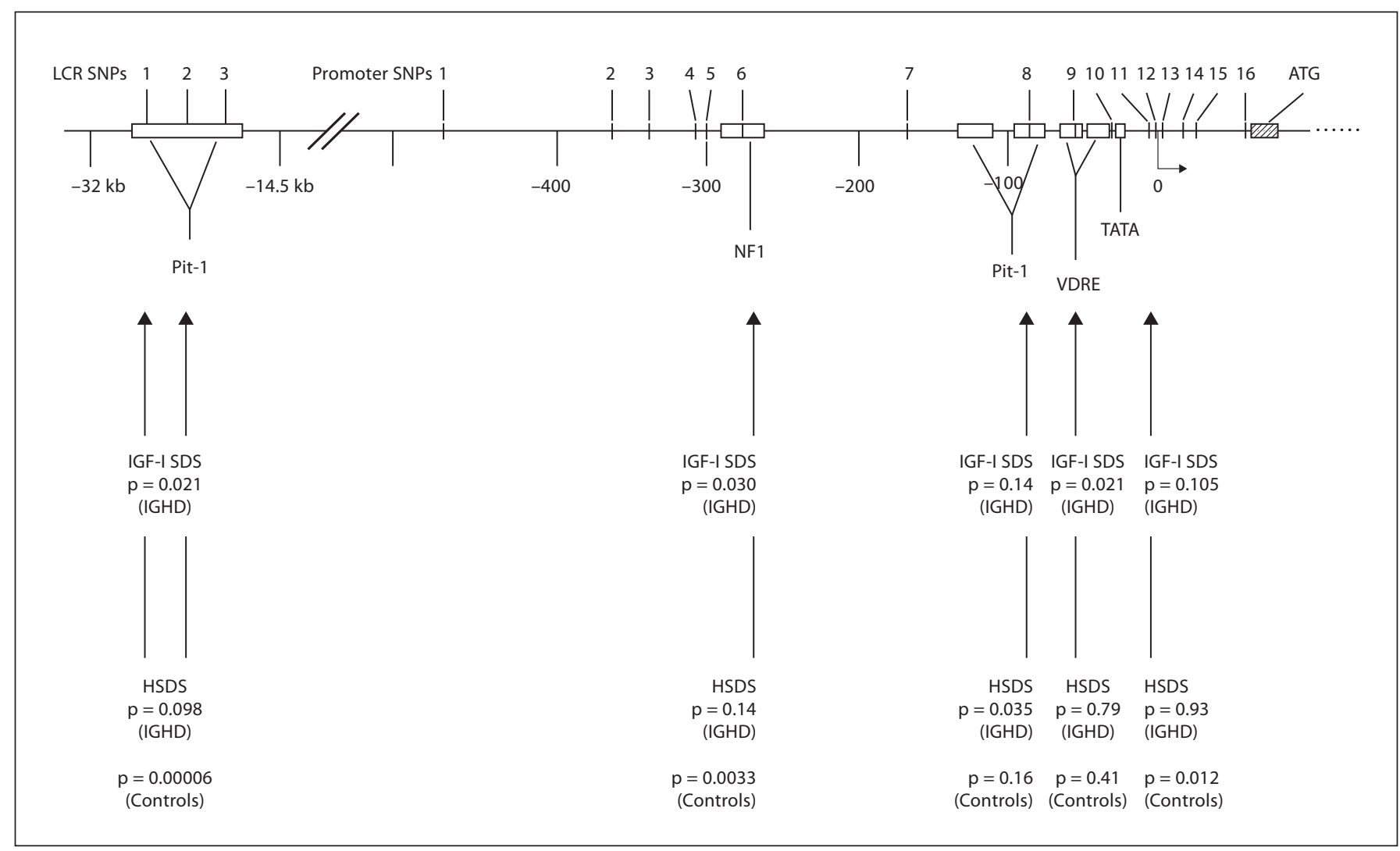

Fig. 2. GH1 promoter and LCR SNPs genotyped in this study, the functional regions in which they are located and their associations with clinical data (adapted from Horan et al. [9]). NF1 = Nuclear factor 1; VDRE = vitamin D response element.

Since genotype frequencies and clinical associations differed between IGHD patients and controls, we discuss the results of the IGHD patients and healthy controls separately.

\section{IGHD Patients}

The study population consisted of 43 male and $19 \mathrm{fe}$ male IGHD patients, which is in accordance with a male predominance in the overall Dutch IGHD population. Mean $( \pm \mathrm{SD})$ age at testing was $15.6 \pm 6.4$ years, mean age at the start of GH treatment was $5.7 \pm 2.7$ years. At the start of GH treatment, height SDS was $-3.1 \pm 0.9$ and IGF-I SDS was $-3.3 \pm 2.3$. There were no differences in genotype frequencies, height SDS or IGF-I SDS between males and females.

We found significant differences in height and serum IGF-I levels between carriers of the different genotypes at individual promoter SNPs 6, 8 and 9 (table 2). LCR SNP1, promoter SNP 6 and intron 4 SNP 'P1' (IVS4 +90 T/A) were highly linked (fig. 1). In our population, there was no significant association between the individual intron 4 SNP and peak GH levels, HSDS and IGF-I levels as formerly described by Hasegawa et al. [12] (data not shown).

We did not find any relation between LCR/promoter SNPs and the 1st year response to GH treatment (data not shown).

\section{Controls}

The controls (27 males and 45 females) had a mean ( \pm SD) age at testing of $21.0 \pm 1.6$ years and height SDS of $-0.2 \pm 1.0$. There were no differences in genotype frequencies or height SDS between males and females.

For promoter SNPs 6 and 11, height differed significantly between the carriers of the various genotypes (table 2).

\section{IGHD Patients versus Controls}

We compared promoter SNP genotypes between IGHD patients and controls, and found that homozygos- 
Table 1. SNPs located in the LCR, promoter and intron 4 of GH1

\begin{tabular}{|c|c|c|c|c|}
\hline SNP ID $^{\mathrm{a}}$ & Position ${ }^{\mathrm{b}}$ & Reference & GH1 allele ${ }^{c}$ & Functional region \\
\hline $\operatorname{LCR}$ SNP $1 / 2^{\mathrm{e}}$ & $1194 / 1144$ & rs4968672/rs4968673 & $\mathrm{G} / \mathrm{A}^{\mathrm{f}} / \mathrm{T}^{\mathrm{f}} / \mathrm{G}^{\mathrm{f}}$ & PIT1 \\
\hline LCR SNP 3 & 990 & - & $\mathrm{C} / \mathrm{T}^{\mathrm{f}}$ & PIT1 \\
\hline Prom SNP 1 & -476 & rs41299065 & $\mathrm{G} / \mathrm{A}^{\mathrm{f}}$ & \\
\hline Prom SNP 2 & -364 & - & $\mathrm{G}^{\mathrm{d}}$ & \\
\hline Prom SNP 3 & -339 & rs62636320 & $\mathrm{G} /-^{\mathrm{f}}$ & \\
\hline Prom SNP $4 / 5^{\mathrm{e}}$ & $-308 /-301$ & rs1811081/rs2011732 & $\mathrm{G} / \mathrm{T}^{\mathrm{f}}$ & \\
\hline Prom SNP 6 & -278 & rs2005171 & $\mathrm{G} / \mathrm{T}^{\mathrm{f}}$ & NF1 \\
\hline Prom SNP 7 & -168 & rs2727338 & $\mathrm{T} / \mathrm{C}^{\mathrm{f}}$ & \\
\hline Prom SNP 8 & -75 & rs11568828 & $\mathrm{A} / \mathrm{G}^{\mathrm{f}}$ & PIT1 \\
\hline Prom SNP 9 & -57 & rs2005172 & $\mathrm{G} / \mathrm{T}^{\mathrm{f}}$ & VDR \\
\hline Prom SNP 10 & -31 & rs11568827 & $\mathrm{G} /{ }_{-}^{\mathrm{f}}$ & TATA \\
\hline Prom SNP 11 & -6 & rs6171 & $\mathrm{A} / \mathrm{G}^{\mathrm{f}}$ & TSS \\
\hline Prom SNP 12 & -1 & rs695 & $\mathrm{A} / \mathrm{T}^{\mathrm{f}} / \mathrm{C}^{\mathrm{f}}$ & TSS \\
\hline Prom SNP 13 & +3 & rs6175 & $\mathrm{G} / \mathrm{C}^{\mathrm{f}}$ & TSS \\
\hline Prom SNP 14 & +16 & rs9282699 & $\mathrm{A} / \mathrm{G}^{\mathrm{f}}$ & $5^{\prime}$-UTR \\
\hline Prom SNP 15 & +25 & rs6172 & $\mathrm{A} / \mathrm{C}^{\mathrm{f}}$ & 5'-UTR \\
\hline Prom SNP 16 & +59 & rs6173 & $\mathrm{T} / \mathrm{G}^{\mathrm{f}}$ & $5^{\prime}-\mathrm{UTR}$ \\
\hline GH1 SNP P1 & IVS4+90 & dbSNP 2665802 & $\mathrm{~T} / \mathrm{A}^{\mathrm{f}}$ & Intron 4 \\
\hline
\end{tabular}

TSS = Transcriptional start site; PIT1 = PIT1 binding site; NF1 = nuclear factor 1 binding site; VDR= vitamin $\mathrm{D}$ receptor binding site; Prom = promoter; $-=$ not available.

a SNP identification according to Horan et al. [9]. ${ }^{\text {b }}$ SNP position relative to GH1 transcriptional start site. ${ }^{c}$ The most frequent genotypes in our study at the various promoter SNP sites are in accordance with the expected genotype when sequencing GH1 instead of any of the other four GH1 paralogue genes. ${ }^{\mathrm{d}}$ Only G alleles

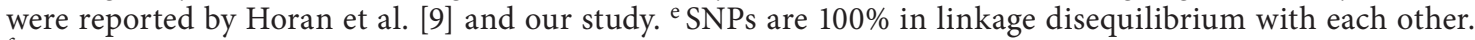
${ }^{\mathrm{f}}$ Minor allele.

Table 2. Frequencies of individual promoter SNPs and their relations with clinical data

\begin{tabular}{|c|c|c|c|c|c|c|}
\hline & & \multicolumn{3}{|c|}{ IGHD patients } & \multicolumn{2}{|l|}{ Controls } \\
\hline & & $\mathrm{n}$ & HSDS & IGF-I SDS & $\mathrm{n}$ & HSDS \\
\hline Promoter SNP 6 & $\begin{array}{l}\text { GG } \\
\text { GT } \\
\text { TT }\end{array}$ & $\begin{array}{c}22(37 \%) \\
32(53 \%) \\
6(10 \%) \\
\mathrm{T}=37 \%\end{array}$ & $\begin{array}{r}-3.3(0.8) \\
-3.1(0.9) \\
-2.5(0.8) \\
p=0.14\end{array}$ & $\begin{array}{c}-4.0(2.6) \\
-3.0(2.0) \\
-1.4(1.2) \\
\mathrm{p}=0.03\end{array}$ & $\begin{array}{l}19(27 \%) \\
42(59 \%) \\
10(14 \%) \\
\mathrm{T}=44 \%\end{array}$ & $\begin{array}{c}0.3(0.7) \\
-0.6(0.9) \\
-0.1(0.8) \\
p=0.003\end{array}$ \\
\hline Promoter SNP 8 & $\begin{array}{l}\text { AA } \\
\text { AG } \\
\text { GG }\end{array}$ & $\begin{array}{c}53(88 \%) \\
7(12 \%) \\
0 \\
G=6 \%\end{array}$ & $\begin{array}{l}-3.2(0.9) \\
-2.5(0.7) \\
- \\
\mathrm{p}=0.04\end{array}$ & $\begin{array}{l}-3.4(2.3) \\
-2.0(1.0) \\
- \\
\mathrm{p}=0.14\end{array}$ & $\begin{array}{c}63(87 \%) \\
7(10 \%) \\
2(3 \%) \\
G=8 \%\end{array}$ & $\begin{array}{r}-0.3(0.9) \\
-0.6(0.8) \\
0.8(1.2) \\
p=0.16\end{array}$ \\
\hline Promoter SNP 9 & $\begin{array}{l}\text { GG } \\
\text { GT } \\
\text { TT }\end{array}$ & $\begin{array}{l}25(42 \%) \\
22(37 \%) \\
13(22 \%)^{* *} \\
\mathrm{~T}=40 \%\end{array}$ & $\begin{array}{c}-3.1(0.8) \\
-3.1(1.1) \\
-3.3(0.8) \\
p=0.8\end{array}$ & $\begin{array}{r}-2.6(1.6) \\
-3.0(2.3) \\
-4.8(2.6) \\
\mathrm{p}=0.02\end{array}$ & $\begin{array}{c}25(35 \%) \\
42(58 \%) \\
5(7 \%) \\
\mathrm{T}=36 \%\end{array}$ & $\begin{array}{r}-0.2(0.9) \\
-0.4(1.0) \\
0.2(0.7) \\
p=0.41\end{array}$ \\
\hline Promoter SNP 11 & $\begin{array}{l}\text { AA } \\
\text { AG } \\
\text { GG }\end{array}$ & $\begin{array}{c}24(40 \%) \\
31(52 \%) \\
5(8 \%) \\
G=34 \%\end{array}$ & $\begin{array}{c}-3.2(0.7) \\
-3.1(1.0) \\
-3.2(0.7) \\
\mathrm{p}=0.9\end{array}$ & $\begin{array}{r}-4.0(2.5) \\
-2.9(2.0) \\
-2.0(1.6) \\
\mathrm{p}=0.10\end{array}$ & $\begin{array}{l}18(25 \%) \\
43(60 \%) \\
11(15 \%) \\
G=45 \%\end{array}$ & $\begin{array}{c}0.0(1.0) \\
-0.6(0.9) \\
0.2(0.9) \\
p=0.012\end{array}$ \\
\hline
\end{tabular}

HSDS = height SDS (for patients at start of GH treatment).

** Homozygosity for the minor allele is more frequent in IGHD patients than in controls, $\mathrm{p}=0.005$. 
Table 3. Frequencies of combined genotypes of promoter SNPs 6, 8, 9 and 11 and their relations with clinical data

\begin{tabular}{|c|c|c|c|c|c|c|c|c|c|c|}
\hline \multicolumn{2}{|c|}{ SNP 6-8-9-11 genotype* } & \multicolumn{6}{|c|}{ IGHD patients } & \multicolumn{3}{|c|}{ Controls } \\
\hline 1 & G/G A/A T/T A/A & 12 & 27.2 & $-3.2(0.8)$ & $12.1(9.2)$ & $9.5(5.1)$ & $-5.0(2.6)$ & 4 & 8.3 & $0.4(0.5)$ \\
\hline 2 & G/G A/A G/T A/A & 5 & 11.4 & $-3.5(0.8)$ & $17.6(1.3)$ & $15.0(7.2)$ & $-2.1(2.3)$ & 6 & 12.5 & $0.5(0.8)$ \\
\hline 3 & $\mathrm{G} / \mathrm{G} \mathrm{A} / \mathrm{A} \mathrm{G} / \mathrm{T}$ A/G & 0 & - & - & - & - & - & 6 & 12.5 & $0.0(0.9)$ \\
\hline 6 & G/T A/G G/G A/G & 3 & 6.8 & $-3.0(0.1)$ & $6.5(5.6)$ & $12.0(0.1)$ & $-2.2(1.7)$ & 1 & 2.1 & -0.4 \\
\hline \multirow[t]{2}{*}{7} & T/T A/A G/G A/G & 3 & 6.8 & $-3.0(0.6)$ & $9.3(5.2)$ & $10.6(6.9)$ & $-1.3(0.7)$ & 0 & - & - \\
\hline & & 44 & 100.0 & & & & & 48 & 100.0 & \\
\hline
\end{tabular}

Data are shown as mean (SD).

* Only genotypes present in at least $5 \%$ of the patients or controls are shown.

${ }^{1}$ Difference in genotype frequencies between IGHD patients and controls; $\mathrm{p}=0.002$.

\footnotetext{
${ }^{2}$ IGF-I SDS difference between genotypes; $\mathrm{p}=0.08$.

${ }^{3}$ Height SDS difference between genotypes; $\mathrm{p}=0.05$.

${ }^{4}$ Peak GH levels did not differ significantly between genotypes (tested by nonparametric Kruskall-Wallis test due to non-normal distribution of the parameters).
}

ity for the minor allele of SNP 9 was more frequent among patients than among controls ( $21 \%$ vs. $7 \%, \mathrm{p}=0.005$, table 2). Since the minor allele at SNP 9 is associated with lower IGF-I levels in patients, this suggests this allele might contribute to impaired GH levels in IGHD patients.

The promoter SNP 12 was tri-allelic with the major allele A occurring in controls in combination with 2 different minor alleles (AC and AT, frequencies AA 74\%/AT $19 \% /$ AC $5 \% /$ TT $1 \%$ ), whereas in patients, only the AT genotype was present. Among controls, there was no difference in height SDS between individuals with the AC and those with the AT genotype.

For promoter SNP 13, the minor allele was present in 4 of 72 controls (6\%), whereas all 62 patients were homozygous for the major allele $(\mathrm{p}=0.124)$. For the remaining SNPs, genotype and allele frequencies were similar for patients and controls.

\section{Multiple Regression}

The promoter SNPs that were associated with height and/or IGF-I levels in patients or controls (SNPs 6, 8, 9 and 11) were present in 23 different combinations ('SNP 6-8-9-11 genotypes'), of which 7 were present in at least $5 \%$ of the patients or controls (table 3 ). Only 48 controls and 44 patients carried these 7 most frequent combined genotypes; clinical data of the patients and controls with these genotypes are shown in table 3.
Backward multiple regression showed that the 'SNP 6-8-9-11 genotypes' (numbered 1-7 according to table 3) explained $10.8 \%$ of the variation in IGF-I SDS in IGHD patients (adjusted $\mathrm{R}^{2} 0.108, \mathrm{p}=0.02$ ). In controls, the 'SNP 6-8-9-11 genotypes' explained $15.9 \%$ of HSDS variation $\left(\mathrm{R}^{2} 0.159, \mathrm{p}=0.003\right)$.

\section{Discussion}

We analyzed GH1 LCR/promoter SNPs in IGHD patients without mutations or deletions in $G H 1$ or GHRHR, and examined whether these SNPs were associated with height, serum IGF-I levels and response to GH treatment in order to explain the phenotypic variability present among IGHD patients. We compared patients' data with those of a normal control group and found that homozygosity for the minor allele of SNP 9 was more frequent among patients than among controls $(21 \%$ vs. $7 \%, \mathrm{p}=$ 0.005). The minor allele at SNP 9 was associated with lower IGF-I levels in patients, suggesting that this allele might contribute to impaired GH production in IGHD patients. Also SNP 6, 8 and 11 were related with height and IGF-I levels.

LCR SNPs 1 and 2, promoter SNP 6 and intron 4 SNP 'P1' (IVS4 +90 T/A; only available for IGHD patients) were highly linked. However, in contrast to Hasegawa et al. [12], we did not find any significant association between the individual intron 4 SNP and peak GH levels, HSDS, 
and IGF-I levels in our population (data not shown), whereas we did find significant associations between LCR SNPs 1 and 2 and growth-related parameters, as well as between promoter SNP 6 and these parameters (fig. 2). This suggests that the relation between the intron 4 SNP and growth-related parameters reported by Hasegawa et al. [12], might actually be caused by its linkage with LCR SNPs 1 and 2 or promoter SNP 6, which, in our study, have stronger associations with growth-related parameters, but were not studied by Hasegawa et al. [12].

We tried to combine promoter SNPs 6, 8, 9 and 11 into haplotypes. Although the result of the multiple regression based on these combined genotypes should be interpreted with caution due to the reduced patient number and subsequent power reduction, in our population the combined genotypes explained $10.8 \%$ of the variation in serum IGF-I levels in IGHD patients and $15.9 \%$ of height variation in controls. Although all patients had IGHD according to Dutch consensus criteria, certain genotypes were associated with a relatively mild phenotype.

The impact of individual SNPs can be explained by the fact that the regions in which they are located are important for transcription of GH1. The LCR contains DNase I-hypersensitive sites located at -14.5 to $-32 \mathrm{~kb}$ relative upstream to the $G H 1$ promoter, where the transcription factor PIT1 binds in order to regulate $\mathrm{GH} 1$ transcription. Therefore, LCR SNPs may alter transcription of GH1. SNP 6 is located in the part of the promoter where nuclear factor 1 binds [33]. Binding of nuclear factor 1 to the nuclear factor 1 binding site is necessary for transcription, and variation at this site may alter expression of GH1. Promoter SNP 8 is located in the proximal PIT1 binding site and promoter SNP 9 is located in the region corresponding to the vitamin $\mathrm{D}$ receptor response element. Disturbed binding of PIT1 and the vitamin D receptor to the PIT1 binding site and vitamin $\mathrm{D}$ receptor response element, respectively, may alter transcription and, thus, expression of the GH1 gene. Both SNP 8 and 9 were shown in vitro to interact with nucleic acid binding proteins, and alternative alleles exhibit differential protein binding [9]; SNP 9 showed protein interaction only for the G allele, not the T allele [9]. This is in accordance with our findings in vivo that patients homozygous for the $\mathrm{T}$ allele have very low IGF-I levels (table 2). For SNP 8, Esteban et al. [10] demonstrated a lower HSDS in carriers of the alternate allele in a control normal height adult population; Giordano demonstrated a diminished transcriptional activity for the alternate allele [11]. For SNP 9, Giordano demonstrated diminished GH secretion in alternate allele carriers
[34]. SNP 11 is located in the transcriptional start site of $\mathrm{GH1}$; therefore, variation at this site may alter efficacy of transcription, leading to varying levels of $G H 1$ expression. Probably, the effect of the promoter SNPs is the sum of individual SNP effects and effects based on combinations with other SNPs. Variation at 1 individual SNP site can cause altered binding of the corresponding protein. This altered binding can in turn affect the binding of a 2nd protein at another SNP site, but the extent to which the binding of this 2 nd protein is affected will also depend on the variation at the 2 nd SNP site.

Associations between LCR/promoter SNPs with height and IGF-I levels are likely to be mediated by GH levels in serum, which may vary due to altered expression of GH1. Although the variation in IGF-I SDS between the different genotypes was largely in accordance with the variations in peak GH levels obtained during GH stimulation tests, the association between the genotypes and peak $\mathrm{GH}$ levels was not significant (table 3). The fact that IGF-I levels are associated with LCR/promoter SNPs, whereas stimulated GH levels are not, may be explained by the fact that forced GH secretion during a stimulation test does not always reliably reflect the spontaneous GH secretion pattern. Due to the fact that it reflects spontaneous daily GH secretion, serum IGF-I is considered a more reliable indicator of spontaneous GH secretion than GH peaks during stimulation tests [35-37]. Therefore, although LCR/promoter SNPs are not significantly related to peak $\mathrm{GH}$ levels obtained during stimulation tests, the relation of these SNPs with height and IGF-I levels is probably mediated by altered spontaneous $\mathrm{GH}$ secretion.

The LCR/promoter SNP genotype frequencies and clinical associations differed between IGHD patients and healthy controls. These differences may be explained by the fact that certain genotypes could be beneficial for processes that take place in IGHD patients, but not in controls, due to the altered GH/IGF-I status.

Although all controls had a height within the normal range, the lowest height SDS were found in patients heterozygous for promoter SNPs 6 and 11. This association with shorter stature was specific for the heterozygous state, since controls homozygous for the minor allele had a higher HSDS. The finding that the heterozygous state is associated with a certain phenotype and differs from the 2 homozygous states, has been previously reported and is the subject of research and discussion [9, 38-47]. Heterozygous advantage or disadvantage of promoter SNPs may be explained by allele-dependent regulation of gene expression. A key process in allele-dependent regulation of gene expression is trans-regulation, which means 
that an enhancer from 1 allele acts in trans to activate transcription from the promoter of the 2 nd allele $[45,46$, 48]. Transcription factors can bind 2 DNA molecules simultaneously, functioning as a protein bridge and mediating enhancer-promoter communication between 2 homologues [49]. Trans-regulation, i.e. the interaction of 2 alleles in trans, might explain advantages or disadvantages of heterozygosity as found in several studies $[50,51]$ and in SNPs 6 and 11 in our study.

Recently, a map of GH1 promoter SNPs in a Spanish adult control population with normal height was reported [10]. The investigators found 11 SNPs in the promoter region, of which 2 (corresponding to SNPs 8 and 14 in our study) were related to HSDS. The studied promoter SNPs accounted for $6.2 \%$ of adult height determination in the adult Spanish population. Horan et al. [9] studied GH1 LCR and promoter SNPs in relation to height, and found that $3.3 \%$ of the variance of adult height was explained by promoter haplotypes. Our study largely analyzed the same set of promoter SNPs as studied by Horan et al. [9] and Esteban et al. [10], but instead of including all promoter SNPs in the combined genotype analysis, our study focused on the SNPs 6, 8, 9 and 11, as they were individually associated with height or IGF-I levels. Our study analyzed combined SNP 6-8-9-11 genotypes with frequencies above $5 \%$. These most frequent combined genotypes were present in $73 \%$ of the patients and $68 \%$ of the controls. Although genotype numbers were small and results should be interpreted with caution, SNP 6-8-9-11 genotypes explained $10.8 \%$ of IGF-I SDS in the IGHD patients $(\mathrm{p}=0.02)$ and $15.9 \%$ of HSDS in controls $(\mathrm{p}=0.003)$. Such a strong association between promoter SNPs with height and serum IGF-I levels has not previously been described, and this may be due to the different approach and the number of SNPs included in the combined genotype analysis. By limiting the number of SNPs included in the combined genotypes to those that were individually associated with height or IGF-I, we have narrowed the window of promoter SNPs that seem clinically relevant for GH expression, height and IGF-I.

In conclusion, homozygosity for the minor allele of SNP 9 was significantly more frequent among patients than among controls. Since this minor allele at SNP 9 was associated with lower IGF-I levels in IGHD patients, our data suggests that this allele might contribute to impaired GH production in IGHD patients. Apart from SNP 9, SNP 6, 8 and 11 were also related with height and IGF-I levels.

\section{Acknowledgements}

This study was supported by the Dutch Growth Foundation, the Spanish 'Fundación Endocrinología y Nutrición' and grants from the Spanish Ministry of Health (FIS C03/07 and PI051675 to J.A.). We thank all patients and their parents for participating in the study. We acknowledge pediatric endocrinologists S.L.S. Drop, Erasmus Medical Center/Sophia Children's Hospital; M. Jansen, University Medical Center of Utrecht/Wilhelmina Children's Hospital; B. Otten, University Medical Center of Nijmegen; C.W. Rouwé, University Medical Center of Groningen, P.G. Voorhoeve, VU Medical Center of Amsterdam and J.M. Wit, Leiden University Medical Center, for their collaboration. We thank endocrinologist M. Drent for providing data from the Dutch National Registry of Growth Hormone Treatment in Adults. We thank Esther de Beus (research assistant) for practical coordination of the study and for collection of blood samples and clinical data; Bonnie Bakri, Matthieu van der Vlist and Janneke Baan, (medical students) for their help during collection of clinical data; and Mila Jhamai and Michael Verbiest for technical assistance at the Genetic Laboratory of the Department of Internal Medicine at Erasmus Medical Center of Rotterdam.

\section{References}

1 Goldenberg N, Barkan A: Factors regulating growth hormone secretion in humans. Endocrinol Metab Clin North Am 2007;36:3755.

2 Fofanova OV, Evgrafov OV, Polyakov AV, Poltaraus AB, Peterkova VA, Dedov II: A novel IVS2 $-2 \mathrm{~A}>\mathrm{T}$ splicing mutation in the GH-1 gene in familial isolated growth hormone deficiency type II in the spectrum of other splicing mutations in the Russian population. J Clin Endocrinol Metab 2003;88:820-826.

-3 Miyata I, Eto Y, Kamijo T, Ogawa M, Futrakul A, Phillips JA III: Screening for mutations in the GH-1 gene by dideoxy fingerprinting (ddF). Endocr J 1999;46(suppl): S71-S74.
4 Ogawa M, Kamijo T, Igarashi Y, Nishi Y, Iwatani N, Kohno H, Koga J, Byun YJ: Prevalence of GH-1 gene deletion in patients with isolated growth hormone deficiency in Japan. GH Gene Study Group. Endocr J 2000; 47:157-162.

5 Osorio MG, Marui S, Jorge AA, Latronico AC, Lo LS, Leite CC, Estefan V, Mendonca BB, Arnhold IJ: Pituitary magnetic resonance imaging and function in patients with growth hormone deficiency with and without mutations in GHRH-R, GH-1, or PROP-1 genes. J Clin Endocrinol Metab 2002;87: 5076-5084
6 Salvatori R, Fan X, Phillips JA III, EspigaresMartin R, Martin DL I, Freeman KL, Plotnick L, Al Ashwal A, Levine MA: Three new mutations in the gene for the growth hormone (gh)-releasing hormone receptor in familial isolated gh deficiency type ib. J Clin Endocrinol Metab 2001;86:273-279.

7 Wagner JK, Eble A, Hindmarsh PC, Mullis PE: Prevalence of human GH-1 gene alterations in patients with isolated growth hormone deficiency. Pediatr Res 1998;43:105110 .

8 Jones BK, Monks BR, Liebhaber SA, Cooke NE: The human growth hormone gene is regulated by a multicomponent locus control region. Mol Cell Biol 1995;15:7010-7021. 
\9 Horan M, Millar DS, Hedderich J, Lewis G, Newsway V, Mo N, Fryklund L, Procter AM, Krawczak M, Cooper DN: Human growth hormone 1 (GH1) gene expression: complex haplotype-dependent influence of polymorphic variation in the proximal promoter and locus control region. Hum Mutat 2003;21: 408-423.

10 Esteban C, Audi L, Carrascosa A, Fernandez-Cancio M, Perez-Arroyo A, Ulied A, Andaluz P, Arjona R, Albisu M, Clemente M, Gussinye M, Yeste D: Human growth hormone (GH1) gene polymorphism map in a normal-statured adult population. Clin Endocrinol (Oxf) 2007;66:258-268.

11 Giordano M, Godi M, Giacopelli F, Lessi M, Mellone S, Paracchini R, Petri A, Bellone J, Ravazzolo R, Bona G, Momigliano-Richiardi P: A variation in a Pit-1 site in the growth hormone gene (GH1) promoter induces a differential transcriptional activity. Mol Cell Endocrinol 2006;249:51-57.

12 Hasegawa Y, Fujii K, Yamada M, Igarashi Y, Tachibana K, Tanaka T, Onigata K, Nishi Y, Kato S, Hasegawa T: Identification of novel human GH-1 gene polymorphisms that are associated with growth hormone secretion and height. J Clin Endocrinol Metab 2000; 85:1290-1295.

13 Le Marchand L, Donlon T, Seifried A, Kaaks R, Rinaldi S, Wilkens LR: Association of a common polymorphism in the human GH1 gene with colorectal neoplasia. J Natl Cancer Inst 2002;94:454-460.

14 Wagner JK, Eble A, Cogan JD, Prince MA, Phillips JA III, Mullis PE: Allelic variations in the human growth hormone-1 gene promoter of growth hormone-deficient patients and normal controls. Eur J Endocrinol 1997; 137:474-481.

15 Chanock S: Candidate genes and single nucleotide polymorphisms (SNPs) in the study of human disease. Dis Markers 2001;17:8998.

16 Kao SL, Chong SS, Lee CG: The role of single nucleotide polymorphisms (SNPs) in understanding complex disorders and pharmacogenomics. Ann Acad Med Singapore 2000; 29:376-382.

17 Suh Y, Vijg J: SNP discovery in associating genetic variation with human disease phenotypes. Mutat Res 2005;573:41-53.

18 Wang X, Chen D, Niu T, Wang Z, Wang L, Ryan L, Smith T, Christiani DC, Zuckerman $\mathrm{B}, \mathrm{Xu} \mathrm{X}$ : Genetic susceptibility to benzene and shortened gestation: evidence of geneenvironment interaction. Am J Epidemiol 2000;152:693-700.

19 Baralle M, Baralle FE: Genetics and molecular biology: single nucleotide polymorphism associations and their functional significance. Curr Opin Lipidol 2006;17:360-362.

20 Cartegni L, Chew SL, Krainer AR: Listening to silence and understanding nonsense: exonic mutations that affect splicing. Nat Rev Genet 2002;3:285-298.
21 Mendell JT, Sharifi NA, Meyers JL, Martinez-Murillo F, Dietz HC: Nonsense surveillance regulates expression of diverse classes of mammalian transcripts and mutes genomic noise. Nat Genet 2004;36:1073-1078.

22 Liao G, Wang J, Guo J, Allard J, Cheng J, Ng A, Shafer S, Puech A, McPherson JD, Foernzler D, Peltz G, Usuka J: In silico genetics: identification of a functional element regulating $\mathrm{H} 2$-Ealpha gene expression. Science 2004;306:690-695.

23 Adkins RM, Campese C, Vaidya R, Boyd TK: Association between fetal growth restriction and polymorphisms at sites -1 and +3 of pituitary growth hormone: a case-control study. BMC Pregnancy Childbirth 2005;5:2.

24 Dennison EM, Syddall HE, Rodriguez S, Voropanov A, Day IN, Cooper C: Polymorphism in the growth hormone gene, weight in infancy, and adult bone mass. J Clin Endocrinol Metab 2004;89:4898-4903.

25 Canzian F, McKay JD, Cleveland RJ, Dossus L, Biessy C, Boillot C, Rinaldi S, Llewellyn $\mathrm{M}$, Chajes V, Clavel-Chapelon F, Tehard B, Chang-Claude J, Linseisen J, Lahmann PH, Pischon T, Trichopoulos D, Trichopoulou A, Zilis D, Palli D, Tumino R, Vineis P, Berrino F, Bueno-de-Mesquita $\mathrm{HB}$, van Gils $\mathrm{CH}$, Peeters PH, Pera G, Barricarte A, Chirlaque MD, Quiros JR, Larranaga N, MartinezGarcia C, Allen NE, Key TJ, Bingham SA, Khaw KT, Slimani N, Norat N, Riboli E, Kaaks R: Genetic variation in the growth hormone synthesis pathway in relation to circulating insulin-like growth factor-I, insulin-like growth factor binding protein-3, and breast cancer risk: results from the European prospective investigation into cancer and nutrition study. Cancer Epidemiol Biomarkers Prev 2005;14:2316-2325.

26 Mulhall C, Hegele RA, Cao H, Tritchler D, Yaffe M, Boyd NF: Pituitary growth hormone and growth hormone-releasing hormone receptor genes and associations with mammographic measures and serum growth hormone. Cancer Epidemiol Biomarkers Prev 2005; 14:2648-2654.

27 Ren Z, Cai Q, Shu XO, Cai H, Cheng JR, Wen WQ, Gao YT, Zheng W: Genetic polymorphisms in the human growth hormone-1 gene $(\mathrm{GH} 1)$ and the risk of breast carcinoma. Cancer 2004;101:251-257.

28 Wagner K, Hemminki K, Israelsson E, Grzybowska E, Klaes R, Chen B, Butkiewicz D, Pamula J, Pekala W, Forsti A: Association of polymorphisms and haplotypes in the human growth hormone 1 (GH1) gene with breast cancer. Endocr Relat Cancer 2005; 12: 917-928.

29 de Graaff LC, Argente J, Veenma DC, Herrebout MA, Friesema EC, Uitterlinden AG, Drent ML, Campos-Barros A, Hokken-Koelega AC: Genetic screening of a Dutch population with isolated growth hormone deficiency. Clin Endocrinol (Oxf) 2009;70: 742-750.
30 Rikken B, van Doorn J, Ringeling A, Van den Brande JL, Massa G, Wit JM: Plasma levels of insulin-like growth factor (IGF)-I, IGF-II and IGF-binding protein-3 in the evaluation of childhood growth hormone deficiency. Horm Res 1998;50:166-176.

- 31 Jin Y, Surabhi RM, Fresnoza A, Lytras A, Cattini PA: A role for A/T-rich sequences and Pit-1/GHF-1 in a distal enhancer located in the human growth hormone locus control region with preferential pituitary activity in culture and transgenic mice. Mol Endocrinol 1999;13:1249-1266.

32 Barrett JC, Fry B, Maller J, Daly MJ: Haploview: analysis and visualization of $\mathrm{LD}$ and haplotype maps. Bioinformatics 2005;21: 263-265.

33 Courtois SJ, Lafontaine DA, Lemaigre FP, Durviaux SM, Rousseau GG: Nuclear factorI and activator protein-2 bind in a mutually exclusive way to overlapping promoter sequences and trans-activate the human growth hormone gene. Nucleic Acids Res 1990;18:57-64.

34 Giordano M, Godi M, Mellone S, Petri A, Vivenza $D$, Tiradani $L$, Carlomagno $Y$, Ferrante $\mathrm{D}$, Arrigo T, Corneli G, Bellone S, Giacopelli F, Santoro C, Bona G, Momigliano-Richiardi P: A functional common polymorphism in the vitamin D-responsive element of the GH1 promoter contributes to isolated growth hormone deficiency. J Clin Endocrinol Metab 2008;93:1005-1012.

35 Gandrud LM, Wilson DM: Is growth hormone stimulation testing in children still appropriate? Growth Horm IGF Res 2004;14: 185-194.

36 Hilczer M, Smyczynska J, Stawerska R, Lewinski A: Stability of IGF-I concentration despite divergent results of repeated $\mathrm{GH}$ stimulating tests indicates poor reproducibility of test results. Endocr Regul 2006;40: $37-45$.

37 Seminara S, Filpo A, Piccinini P, La CF, Cappa M, Faedda A, Loche S: Growth hormone $(\mathrm{GH})$ response to $\mathrm{GH}-$ releasing hormone in short children: lack of correlation with endogenous nocturnal GH secretion. J Endocrinol Invest 1997;20:118-121.

38 Beckman L, Bronnestam R, Cedergren B, Liden S: HL-A antigens, blood groups, serum groups and red cell enzyme thypes in psoriasis. Hum Hered 1974;24:496-506.

39 Comings DE, Gonzalez N, Wu S, Gade R, Muhleman D, Saucier G, Johnson P, Verde R, Rosenthal RJ, Lesieur HR, Rugle LJ, Miller WB, MacMurray JP: Studies of the 48 bp repeat polymorphism of the DRD4 gene in impulsive, compulsive, addictive behaviors: Tourette syndrome, ADHD, pathological gambling, and substance abuse. Am J Med Genet 1999;88:358-368.

40 Comings DE: Molecular heterosis as the explanation for the controversy about the effect of the DRD2 gene on dopamine $\mathrm{D} 2$ receptor density. Mol Psychiatry 1999;4:213-215. 
41 Comings DE, MacMurray JP, Gonzalez N, Ferry L, Peters WR: Association of the serotonin transporter gene with serum cholesterol levels and heart disease. Mol Genet Metab 1999;67:248-253.

42 Frohlander N, Stjernberg N: Association between haptoglobin groups and hereditary predisposition for bronchial asthma. Hum Hered 1989;39:7-11.

43 Keeney S, Kleckner N: Communication between homologous chromosomes: genetic alterations at a nuclease-hypersensitive site can alter mitotic chromatin structure at that site both in cis and in trans. Genes Cells 1996;1:475-489.

44 Muller HP, Schaffner W: Transcriptional enhancers can act in trans. Trends Genet 1990; 6:300-304.
45 Ronshaugen M, Levine M: Visualization of trans-homolog enhancer-promoter interactions at the Abd-B Hox locus in the Drosophila embryo. Dev Cell 2004;7:925932.

46 D’Aiuto L, De Marco R, Edward N, Rizzo A, Chaillet JR, Montecalvo A, Lotze MT, Gambotto A: Evidence of the capability of the CMV enhancer to activate in trans gene expression in mammalian cells. DNA Cell Biol 2006;25:171-180.

47 Duvillie B, Bucchini D, Tang T, Jami J, Paldi A: Imprinting at the mouse Ins2 locus: evidence for cis- and trans-allelic interactions. Genomics 1998;47:52-57.

48 Sipos L, Gyurkovics H: Long-distance interactions between enhancers and promoters. FEBS J 2005;272:3253-3259.
49 Mahmoudi T, Katsani KR, Verrijzer CP GAGA can mediate enhancer function in trans by linking two separate DNA molecules. EMBO J 2002;21:1775-1781.

50 Bozzini C, Girelli D, Bernardi F, Ferraresi P, Olivieri O, Pinotti M, Martinelli N, Manzato F, Friso S, Villa G, Pizzolo F, Beltrame F, Corrocher R: Influence of polymorphisms in the factor VII gene promoter on activated factor VII levels and on the risk of myocardial infarction in advanced coronary atherosclerosis. Thromb Haemost 2004;92:541-549.

51 Fiedorowicz JG, Moser DJ, Hynes SM, Beglinger LJ, Schultz SK, Ellingrod VL: LA allelic heterozygosity of the 5HTTLPR polymorphism is associated with higher cognitive function and lower interpersonal sensitivity. Psychiatr Genet 2007;17:3-4. 